\title{
Combining optimisation and simulation in an energy systems analysis of a Swedish iron foundry
}

Nawzad Mardan and Roger Klahr

\section{Linköping University Post Print}

N.B.: When citing this work, cite the original article.

Original Publication:

Nawzad Mardan and Roger Klahr, Combining optimisation and simulation in an energy systems analysis of a Swedish iron foundry, 2012, Energy, (44), 1, 410-419.

http://dx.doi.org/10.1016/j.energy.2012.06.014

Copyright: Elsevier http://www.elsevier.com/

Postprint available at: Linköping University Electronic Press

http://urn.kb.se/resolve?urn=urn:nbn:se:liu:diva-84636 


\title{
Combining optimisation and simulation in an energy systems analysis of a Swedish iron foundry
}

\author{
Nawzad Mardan $^{\mathrm{a}, *}$, Roger Klahr ${ }^{\mathrm{b}}$ \\ ${ }^{a}$ Department of Management and Engineering, Division of Energy Systems, \\ Linköping University, SE-581 83 Linköping, Sweden \\ ${ }^{\mathrm{b}}$ Swerea SWECAST AB, SE-550 02 Jönköping, Sweden \\ * Corresponding author: fax: +46 (0)13 286687; E-mail address: nawzad.mardan@liu.se
}

\section{ABSTRACT}

To face global competition, and also reduce environmental and climate impact, industrywide changes are needed, especially regarding energy use, which is closely related to global warming. Energy efficiency is therefore an essential task for the future as it has a significant impact on both business profits and the environment. For the analysis of possible changes in industrial production processes, and to choose what changes should be made, various modelling tools can be used as a decision support. This paper uses two types of energy analysis tool: Discrete Event Simulation (DES) and Energy Systems Optimisation (ESO). The aim of this study is to describe how a DES and an ESO tool can be combined. A comprehensive five-step approach is proposed for reducing system costs and making a more robust production system. A case study representing a new investment in part of a Swedish iron foundry is also included to illustrate the method's use. The method described in this paper is based on the use of the DES program QUEST and the ESO tool reMIND. The method combination itself is generic, i.e. other similar programs can be used as well with some adjustments and adaptations.

The results from the case study show that when different boundary conditions are used the result obtained from the simulation tools is not optimum, in other words, the result 
shows only a feasible solution and not the best way to run the factory. It is therefore important to use the optimisation tool in such cases in order to obtain the optimum operating strategy. By using the optimisation tool a substantial amount of resources can be saved. The results also show that the combination of optimisation and simulation tools is useful to provide very detailed information about how the system works and to predict system behaviour as well as to minimise the system cost.

Keywords: Energy efficiency; Integration; Optimisation; Simulation

\section{Introduction}

The threat of global warming is closely related to energy use [1]. Increasing energy prices in recent years and uncertainty concerning future prices have played an important role on the increased focus on energy-related issues worldwide. Furthermore, due to increased globalisation, industries are facing greater competition, forcing them to reduce their costs in order to stay competitive. They also need to develop their production systems by improving quality, improving utilisation of resources and increasing flexibility. In order to reduce both the negative effects on the climate and energy costs, industries must take action to fulfil their part in energy-efficiency measures. Therefore, energy efficiency is an essential task for the future and finding ways to decrease energy use is of great importance. However, there are many barriers to carrying out energy-efficiency measures. For example, it can be a complexity of industrial production systems, where many processes are integrated, having different types of energy carriers and complicated finances, such as taxes, variations in energy prices, material costs and labour costs. 
Therefore, when implementing energy-efficiency measures, this complex interaction has to be considered and one or more modelling tools are needed. However, it has been shown that many of these difficulties may be solved by DES and ESO tools [2-15]. The ESO tool has been used in several industries, such as the Swedish foundry industry [2], steel industry [3, 4] and pulp and paper mills [5, 6], as well as in district heating systems [7] and waste treatment [8]. In these studies the ESO tool is used in order to find the optimal operation strategy, improve energy management systems and investigate how different boundary conditions, such as changes in electricity and fuel prices, influence the system. Simulation in general and DES tool in particular has been widely used in many manufacturing applications and have proven to be an excellent decision support tool for manufacturing system applications [16]. For example, Kursun \& Kalaoglu [17] eliminated the bottlenecks and suggested different decision alternatives in apparel manufacturing using the DES tool. A DES tool has also been used to model energy market dynamics [9] and to investigate the logistics of supplying forest biomass to a power plant [10] as well as in the foundry industry [11-15]. In these examples the DES tool is used to reduce energy use, test different solutions and analyse and plan the production system, where the production process is very complex and disturbances have a large impact on the system.

The solution gained by simulation tools shows feasibility and does not reflect if it is the best way to run a system. To analyse all possible solutions and find the best solution is time-consuming, therefore the optimisation tool is needed in order to obtain the optimum solution in a short time. On the other hand, the solution obtained by the optimisation tool shows the best way to run a system, but does not reflect if the solution is applicable at the 
site or not. Therefore, a simulation tool is needed to validate the solutions provided by the optimisation tool. Moreover, a simulation tool can be used to predict system behaviour, such as blockages, idling and stoppage on a production line, which is quite difficult to model with the optimisation tool.

Therefore, combining the individual strengths of the DES and ESO tools can create prerequisites for decreasing system costs, improving the utilisation of resources, predicting system behaviour and can give very detailed information about how the system operates or works [18]. In many studies, the ESO and DES tools have been combined in such a manner that one of the tools are used at the start and the results that are obtained will then be used in the second tool [19-27]. For example, Erken et al., [22] have combined optimisation and simulation tools to optimise the size of a PV/wind hybrid energy conversion system with battery storage. They used the simulation tool to predict the theoretical distributions of solar radiation and wind speed. From input data provided by the simulation tool, the optimisation tool is used to optimise the PV area, wind turbine rotor swept area, battery capacity and the sizes of the system design parameters.

Despite of the relatively large body of literature on combination between optimization and simulation tools, no detailed procedure exists for describing how such a combination can be implemented step-by-step. In this paper, the ESO and DES are used simultaneously and detail information on how such a combination can be made step-bystep in industrial energy systems is presented. There are iterations processes between the methods and both models are altered during that process in order to verify the other model. 
The combination process between these tools can begin in the early stages of the study, for example in formulation of the problem and setting of objectives [28, 29]. The aim of this paper is to describe how ESO and DES tools can be combined. A comprehensive five-step approach is proposed to show how such a combination can be implemented in practice. Topics to be discussed in the combination methodology include data collection, model construction and validation, result comparison, system optimisation and the verification of results.

The research question in the paper is: how could the DES and ESO tools be combined for non-existing system? The research question was examined using the ESO tool reMIND and DES tool QUEST. These tools were applied in a case study representing a new casting line in a foundry and the paper describes how these two tools are combined.

\section{Method}

\subsection{Energy Systems Optimisation (ESO) tool}

The tool used for ESO is reMIND, which is based on the MIND (Method for analysis of INDustrial energy system) method and was developed at the Division of Energy Systems at Linköping University. The method is based on MILP (Mixed Integer Linear Programming) and was developed to optimize dynamic industrial energy systems. The dynamics of the modelled systems are considered by dividing time into different numbers of time steps, depending on the purpose of the analysis. Information about the method and the tool is found in [30-32] and for applications of the tool in e.g. [2, 6-7, 33-37, 39]. A MILP problem in reMIND is defined according to Equations 1, 2, 3 and 4. 
Objective:

$$
\min Z=f(x, y)
$$

Subject to:

$$
\begin{aligned}
& g(x, y)=0 \\
& h(x, y)\left\{\begin{array}{l}
\leq \\
= \\
\geq
\end{array} C\right. \\
& x \quad 0 ; y \quad\{0,1\}
\end{aligned}
$$

where $f(x ; y)$ is the objective function to be minimised, like system cost, $x$ represent real variables such as amount of electricity consumption for a process, y represent binary variables used to linearise non-linear functions and for logical restrictions, $g(x, y)=0$ are equations describing the performance of the energy system, for example, the relation between the mass flow through a process and the corresponding energy demand, $\mathrm{h}(\mathrm{x}, \mathrm{y})$ are inequalities describing, for example, capacity limits in the system, $\mathrm{C}$ is constant.

Basically, the analysis in reMIND includes four steps $[2,32,37]$. In the first step, the real system has to be delimited. In order to describe the system mathematically, reasonable boundaries must be set, simplifications introduced and processes identified. In the second step, the model is constructed from a set of equations based on the simplifications and delimitations of the problem identified in the initial step, and verification is done so that the description of the system is acceptable [37]. An appropriate optimization routine is applied in the third step. CPLEX [38] is normally used in reMIND. To solve problems, CPLEX chooses among a variety of different algorithms. reMIND is usually use branch and bound to solve the integer programming problems and simplex to solve the linear programming problems in CPLEX. 
In the final step, the results from optimizations are analysed and the model is validated, including verification of the optimal solutions. Furthermore, for verification and discussion of input data to and output data from the model continuous communication with representatives from the company is important in order to create a valid model based on reliable data.

The reMIND tool has been used in several industries, such as the Swedish foundry industry [2], steel industry [4, 35-36] and pulp and paper mills [6, 39] as well as district heating systems [7]. In these studies the ESO tool reMIND is used to find the optimal operation strategy and investigate how different boundary conditions, such as changes in electricity and fuel prices, influence the system.

\subsection{Discrete Event Simulation (DES) tool}

The tool used for DES is QUEST and was developed by Delmia [40]. QUEST belongs to a category of programs that enables the user to build highly accurate models for systems analysis. The tool was originally built for material handling systems and the simulation of industrial production. To accomplish this, discrete mathematics may be used, in which events of various kinds are governing and stored in a queue for each object in the simulation model. An event can be initiated in two ways, either by another event, or at a defined period of time. An example of an event-initiated event is when a machine is at idle and a new product is to begin to be processed in the machine. It is the combination of using time and events that makes the production simulation a powerful tool for analyzing a system. 
QUEST provides a large number of predefined entities, like machines, operators and buffers, which can be configured in the way desired. In more advanced models, like the model described in this paper, the logic needs to be programmed in the built-in Simulation Control Language (SCL). SCL is a procedural language adapted for more unique and complex logic. The term "logic", in this case, is used to describe the decisionmaking activities that occur at specific times during the simulation. Quest has also a builtin 3-D CAD and can import the most common file formats from other CAD programs.

\section{A step-by-step approach to combine methods}

This section describes how the ESO tool reMIND and the DES tool QUEST can be combined. A comprehensive five-step approach, as presented in Figure 1, is proposed. Using the five-step approach, more thorough results may be obtained regarding, for example, the robustness of operation of the production systems and system cost reductions.

\subsection{Step 1-Data collection}

There are several important steps that must be considered before constructing the models. The problem of interest must be clear and addressed from the viewpoint of both methods. The objectives should be clearly defined and formulated so that both methods can be used together in a way that enhances the results of the study [28]. The input data needed by the project should also be identified and collected. Extra focus must be placed on the information that will help to achieve the common objectives of the study. The amount of data that needs to be collected is highly dependent upon system and problem delimitations, project objectives and credibility concerns [28]. The choice of system 


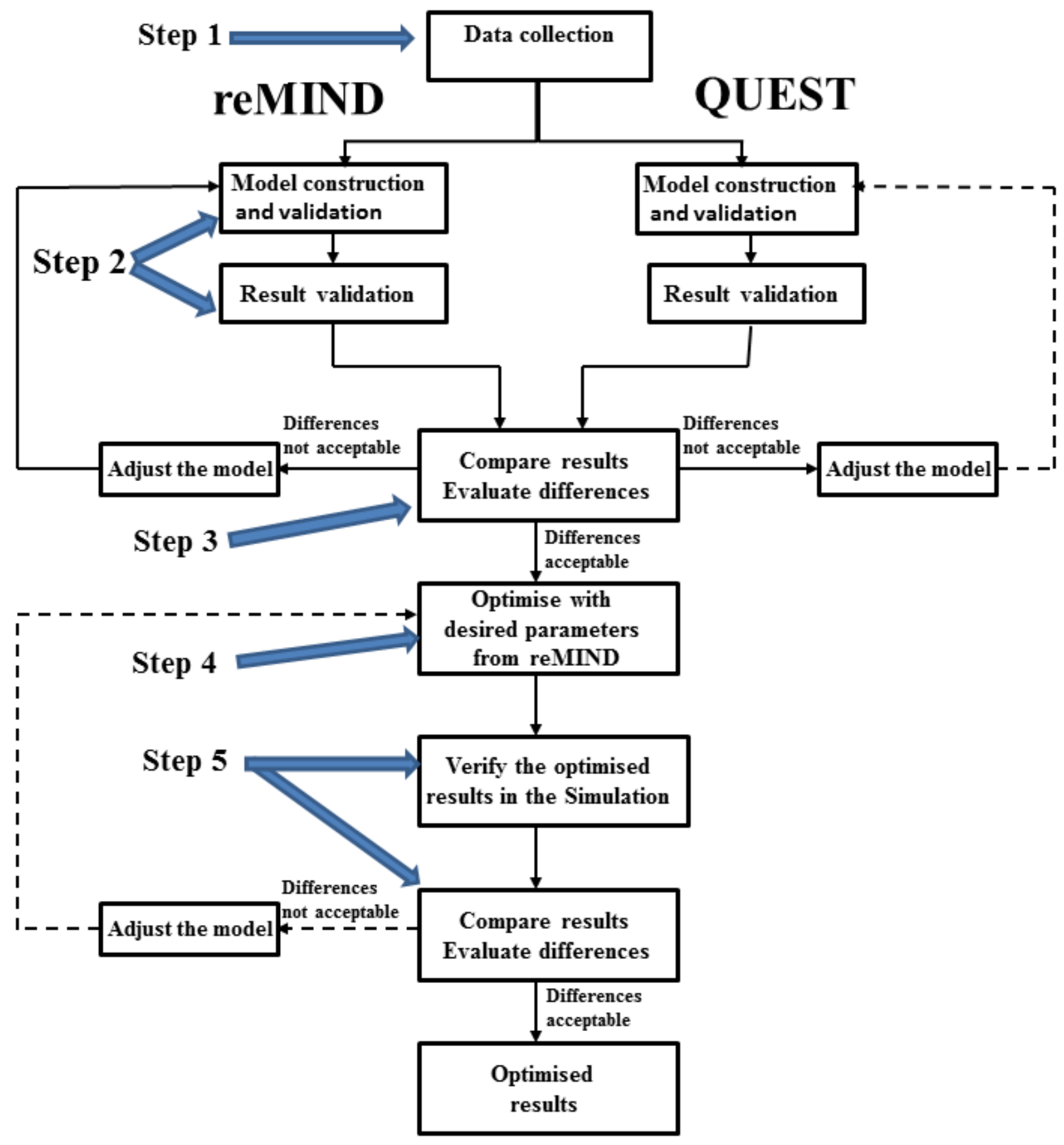

Figure 1 A step-by-step approach to combine methods. 
boundary and setting an appropriate system boundary are therefore vital. For example, it is important to define whether it is the entire industrial energy system or a single process line that is modeled. The system boundary should be set in way that helps to achieve the objectives of the study.

The input data to the ESO and DES models may be common or model specific. The common input data can be, for example, melting capacity, electricity demand for the melting and holding furnaces, efficiency, operator working schedules and processing times. The model-specific data in the ESO model can be, for example, logic input data that describes how different processes are linked to each other and how they run, while in the DES model these can be breakdown time, order list, layout, travel times, Logic (flow description and input devices) and disturbances.

\subsection{Step 2 - Model construction and validation}

The models are built in commercial simulation software and optimisation software, for example, QUEST and reMIND. The models are constructed from a set of equations based on the collected data and delimitations of the problem identified in the previous step. The simulations and optimisations are carried out and a structured walk-through of the model should be done to ensure that the model's earlier performance and assumptions are correct in other words, the models should be verified and validated. The verification of a

model should answer the question of whether the model behaves in the right way, while the validation of the model should answer the question of whether the model is accurate representation of the optimized or simulated system. If errors are found in the model's performance or in the assumptions the model must be updated before proceeding to the result comparison in Step 3. 


\subsection{Step 3-Comparison of results and evaluation of differences}

In the third step, the results are compared and any differences noted and evaluated. The amount of energy used in a process or processes is one type of the types of differences in the results that is highly dependent on resource utilisation and idle time. Another type of difference that has a significant impact on the system might be the number of produced units, which depends on disturbances or stoppages on a production line when a machine breaks down. If errors or differences are found in the results, the simulation or optimisation model must be updated before proceeding to Step 4. The simulation or optimization model is updated by changing the constraints or parameters that need to be changed in the model. For example, it may be a production capacity of a machine, or amount of energy used in a machine or process that needs to be changed. If the modelled system is a real, existing system, the performance measures collected from the existing system are compared with the corresponding performance measures from the simulation and optimisation models.

\subsection{Step 4-Optimisation of the system}

When the simulation and optimisation models are synchronised, different boundary conditions can be used, such as different production process capacity, change in operation hours (for example from a two-shift to a three-shift operation) or a change in energy and raw materials prices. The optimisation model is run to find the optimum operating strategy. In this study, for example, different electricity prices are used in order to investigate how these parameters affect the operating strategy. Different electricity prices are used, due to the fact that the electricity cost constitutes the largest part of the company's energy costs. 


\subsection{Step 5 - Verification of results}

The simulation tool is used to verify, evaluate and test the results from the optimisations. The optimum result should be simulated for two main reasons: first, to analyse and update the simulation and optimisation models if errors or differences (as outlined in Step 3) are found, and second, to investigate if the optimum result can be applied in the simulation model or not. If the optimisation result cannot be applied based on the results from the simulation run, an analysis should be made to show where the work in process is being delayed. There may be feedback loops between the Steps, for example between Step 4 and Step 5.

\section{The modelled system}

\subsection{The foundry under study}

The analysed foundry is located in the south-west of Sweden and mainly manufactures heavy diesel engines for commercial vehicles. The foundry is northern Europe's largest grey iron foundry and produces approximately 150,000 tons of castings annually [41]. The annual energy use is almost $250 \mathrm{GWh}$, of which the largest part is in the form of electricity and coke, the rest is Liquefied Petroleum Gas (LPG). The LPG is used for

preheating the ladles while coke is used for the melting process. Over the past 15 years the company has worked hard to improve its energy efficiency. It has worked on improving the behaviour and attitude of its employees with regard to energy issues and has a well-defined environmental and energy policy. In this study the holding furnace included in the modelled system while the sand preparation is not included. 


\subsection{Investment background}

The foundry decided to invest in a new casting line. The investment includes a moulding line, two melting furnaces (one of which is in operation most of the time), one holding furnace and the ladles that are used to transport molten iron from the furnaces (melting and holding furnaces) to the moulding lines. The new furnace has a melting capacity of 6 tons/hour and uses approximately $600 \mathrm{kWh}$ of electricity per ton of molten iron. The excess heat from production is used to provide local heating.

\section{Model description}

\subsection{The studied system and cases}

The model has been developed to represent an investment in a new casting line. The casting line consists of melting furnaces, a holding furnace, ladle heating, sand preparation and moulding process. Production for one week was modelled, using 120 time steps, representing the hours between 12 p.m. Sunday and 12 p.m. Friday. The foundry operates in two shifts, beginning at 5.30 a.m. and ending at 11.30 p.m., which is 17 hours per day and 85 hours per week in total. In order to investigate the usefulness of the simulation and optimisation method two different cases were devised. The first case uses current electricity prices, where the prices are assumed to remain stable. The other case uses future electricity prices, where electricity prices converge towards 800 SEK/MWh during Monday to Friday between 6 a.m. and 6 p.m. and approximately 440 SEK/MWh during the rest of the week, according to a study by Melkerson et al. [42]. Different electricity prices are used in this study, because the electricity cost constitutes a large part of the company's energy costs. 


\subsection{The optimisation model}

The system modelled in reMIND comprises both production and support processes and is represented as a network of nodes and branches (the square boxes and the arrows, respectively, found in Figure 2). The branches represent flows of any kind, such as material and energy, while the nodes represent a whole process line or a single piece of equipment. The production process begins when the melting furnaces are charged with virgin or scrap iron. The iron is transported via a ladle to the holding furnace, after the melting procedure is finalised. Finally, the melted iron is transported to the pouring station where ready moulds, supplied from the moulding line, are waiting. Figure 2 shows the most important energy and material flows within the system. The objective of this model is to minimise the system cost - the model's system cost in this study comprises only electricity cost, in other words, LPG, labour and material costs are not included. The variables that affect the system cost are the cost of electricity for the processes such as moulding process, cleaning processes, lighting, ventilation, melting and holding processes. The driving force for the model is the production of the final product of the system i.e. 368 tons of iron casting per week.

\subsection{The simulation model}

The modelled system consists of all production processes as well as support processes, as in the ESO tool. The main production processes are:

- Two moulding machines with robots for material handling.

- An ASRS (Automatic Storage and Retrieval System) with two cranes.

- A grading station for moulds. 


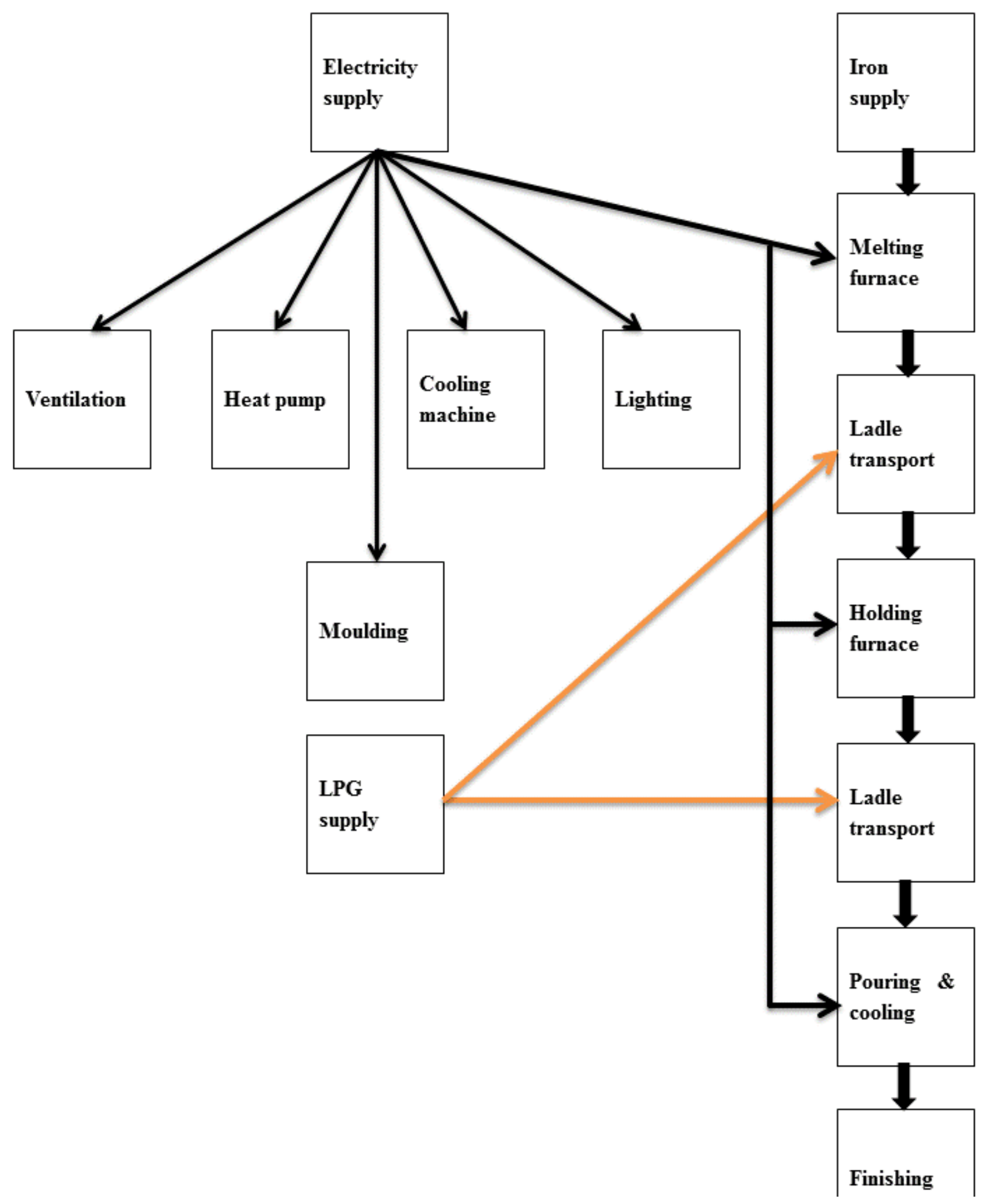

Figure 2 A schematic outline of the modelled system. The arrows represent different flows of electricity, LPG, iron for melting and finished product. 
- An assembly station for moulds.

- A coating station for moulds.

- An oven for drying moulds.

- A pouring and cooling station.

- A melting furnace.

- A holding furnace.

- A casting shakeout.

- Two pallet systems for transporting the moulds between the processes.

The support processes are: lighting, ventilation, cooling machine and heat pumps. The simulation model has been built in 3-D based on information from the factory. Typical input data which is entered into the processes are cycle and set-up times, Mean Time Between Failure (MTBF) and Mean Time TO Repair (MTTR), number of pallets in the two transport systems and speeds for the material handling equipment in the model. The input data for the energy use for processes has been separate in three different states: one state for when the process is in operation, one state when the process is running idle and one state when there is equipment failure or equipment is blocked, preventing production. The model has been simulated with the same input data for energy prices as the reMIND model during the same time, in this case for one week of production. 


\section{Results}

This section provides results according to the step-by-step approach described in Section 3 (see Figure 1). When the input data are collected and the models are built using the reMIND and QUEST tools, a structured walk-through of the model is implemented to ensure the model's performance and the assumptions are correct and complete (Steps 1

and 2). The results from the DES and ESO models are compared (Step 3) and the comparison of the results can be seen in Figure 3. The results from Figure 3 show that the amount of finished product is less in the DES model than in the ESO model, due to the fact that the DES tool takes into account disturbances, such as lack of raw materials, blockages or stoppages on a production line. This kind of disturbance is difficult to estimate or model with the ESO tool, therefore the quantity of finished product will be larger in the ESO model. It also shows that the electricity consumption for moulding, melting and holding processes per ton are less in the ESO model than in the DES model, due to more resources being utilised. This is, in fact, only due to the increase in production, which appears to increase the energy efficiency of this process.

In order to synchronise the models and take into account more realistic data and dynamic changes in the system the ESO model is updated so that the quantity of finished product will be the same as in the DES model. The ESO model is run and a comparison of the results can be seen in Figure 4. 


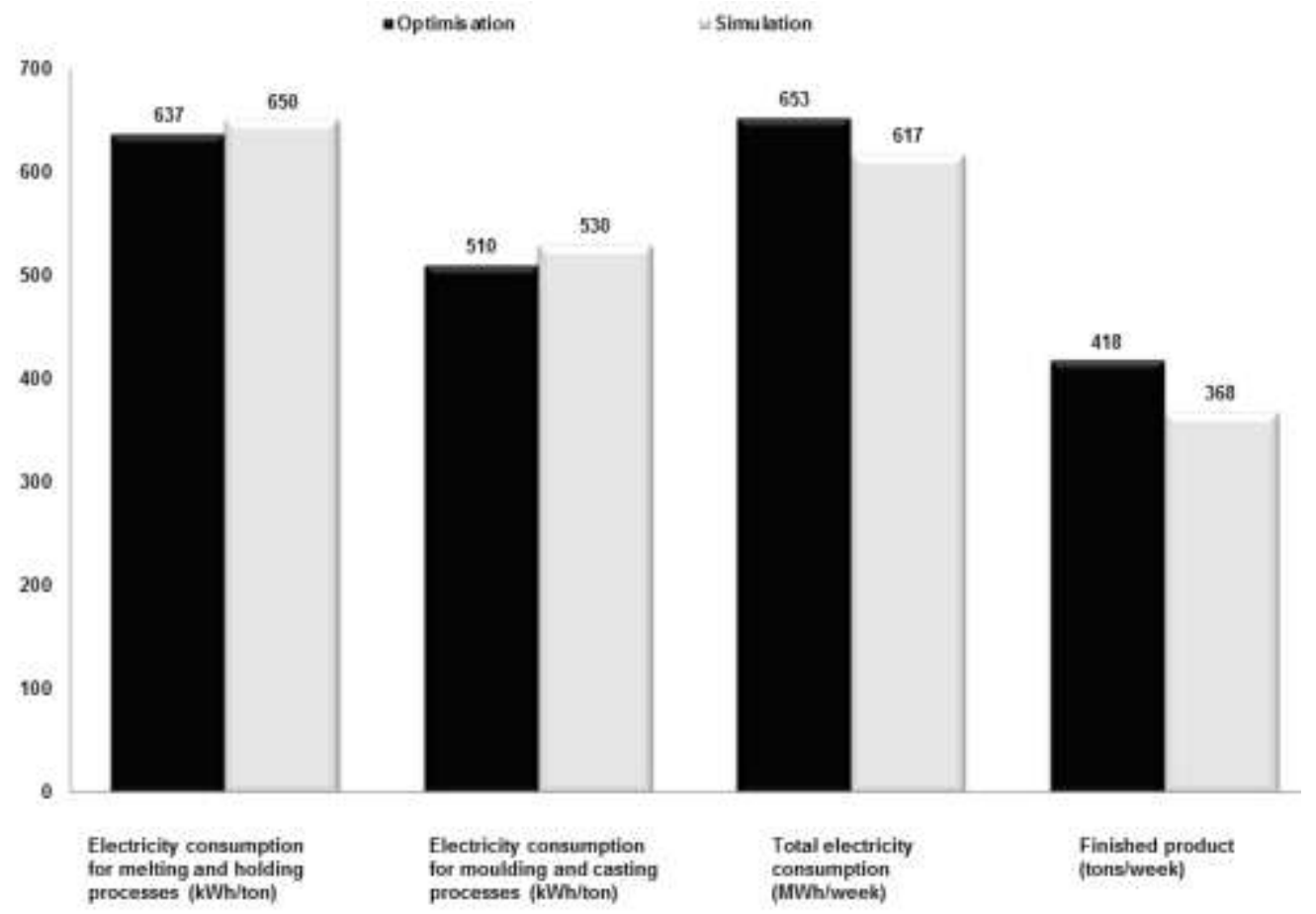

Figure 3 The results from simulation and optimisation tools for different processes.

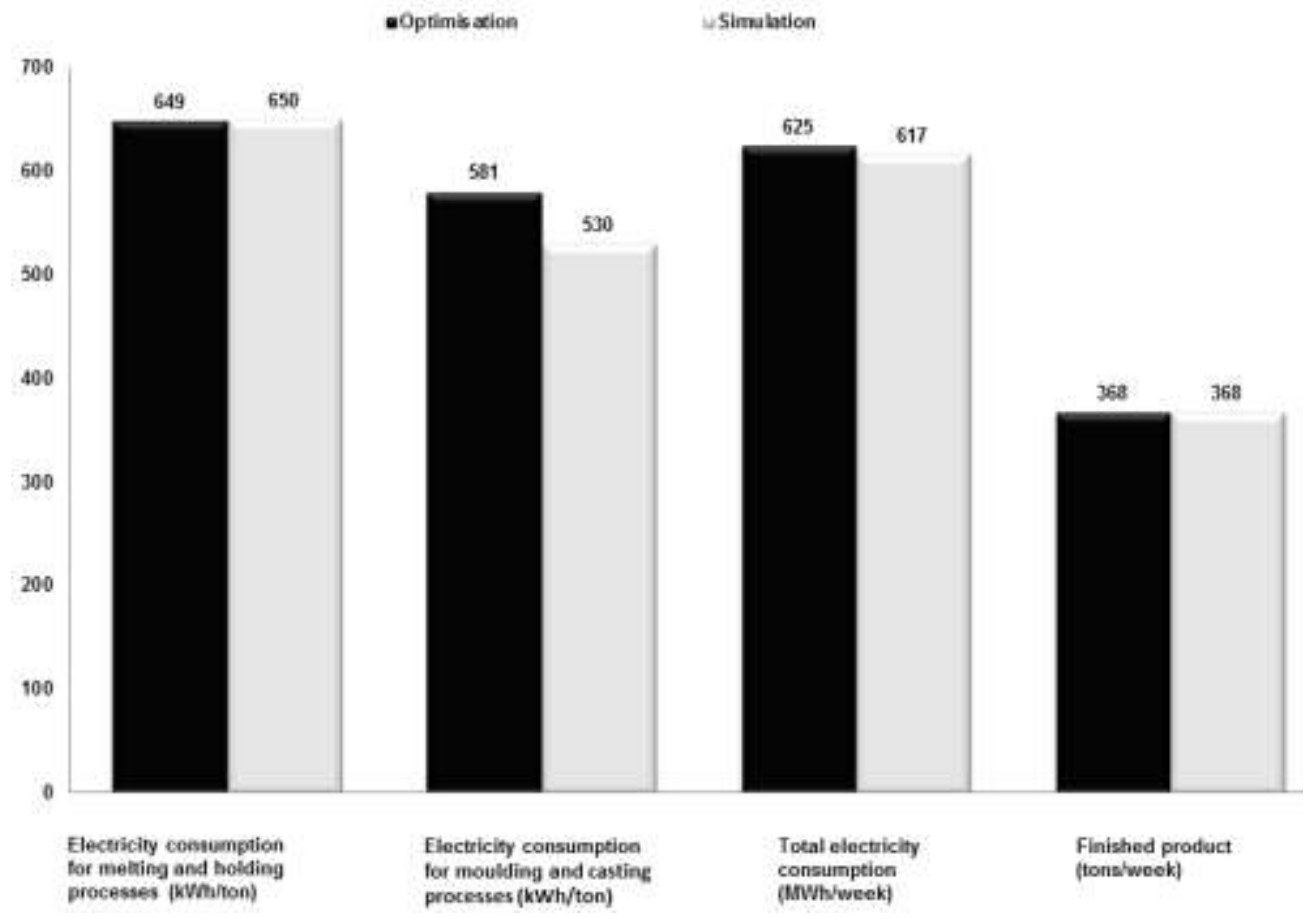

Figure 4 The results from simulation and optimisation tools for different processes after adjustment of the ESO model. 
As shown in Figure 4, electricity consumption for a moulding and casting process is higher in the optimisation results than the simulation results. The reason for this is that the ESO model presumes that the processes are always in operation mode and, as a result, at maximum power, i.e. the rated power, is always used. In the simulation, however, different power demand levels are used, depending on the status of the process, i.e. if the process is in operation mode, if it is in idle mode or if it is blocked. Figure 5 shows results from the DES tool that indicate different states of the processes in the moulding process. The electricity consumption for the processes will vary over time and depend on the process's mode. Figure 6 shows electricity consumption for Operation 1, which shows that Operation 1 is running or in operation mode only $70 \%$ of the time, the rest of the time it is in idle mode because of either idling or blocking. Therefore, the electricity consumption for the moulding and casting process is smaller in the simulation model if it is compared with the optimisation model.

Since the optimization model cannot easily represent a process's mode such as idling and blocking or stoppages when a machine breaks down, the average power for the moulding and casting processes are used in the ESO model instead of maximum power i.e., the ESO model is further updated in order to synchronise the models. The ESO model is run and a comparison of the results can be seen in Figure 7.

Figure 7 shows that the electricity consumption for melting, holding, casting and moulding processes in both models is almost the same. The small differences that exist in electricity consumption are because different tools are used. After synchronisation the models are run and energy costs are compared. The energy cost comparison from the DES and ESO models can be seen in Figure 8. 


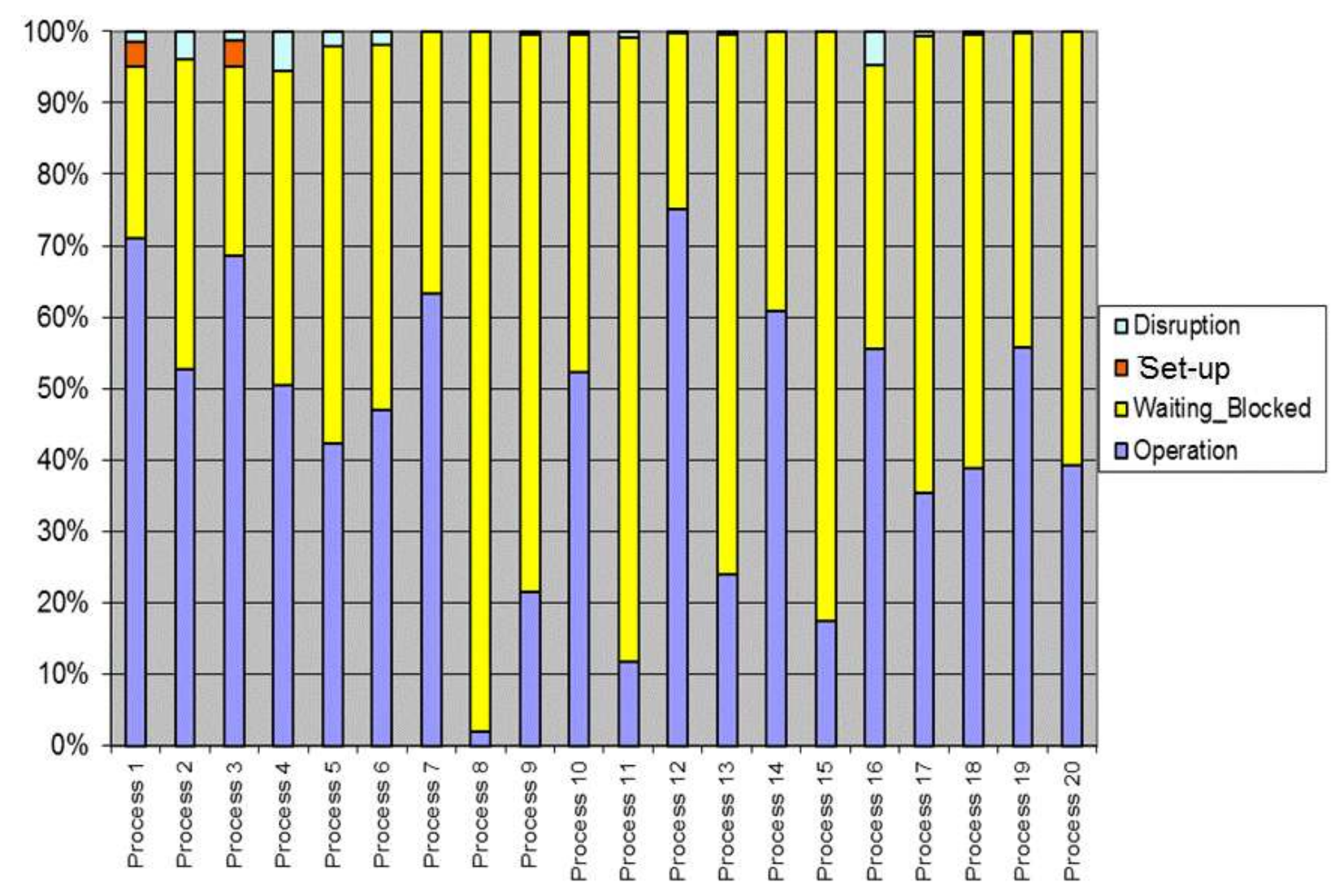

Figure 5 The results from the DES tools show various status of processes.

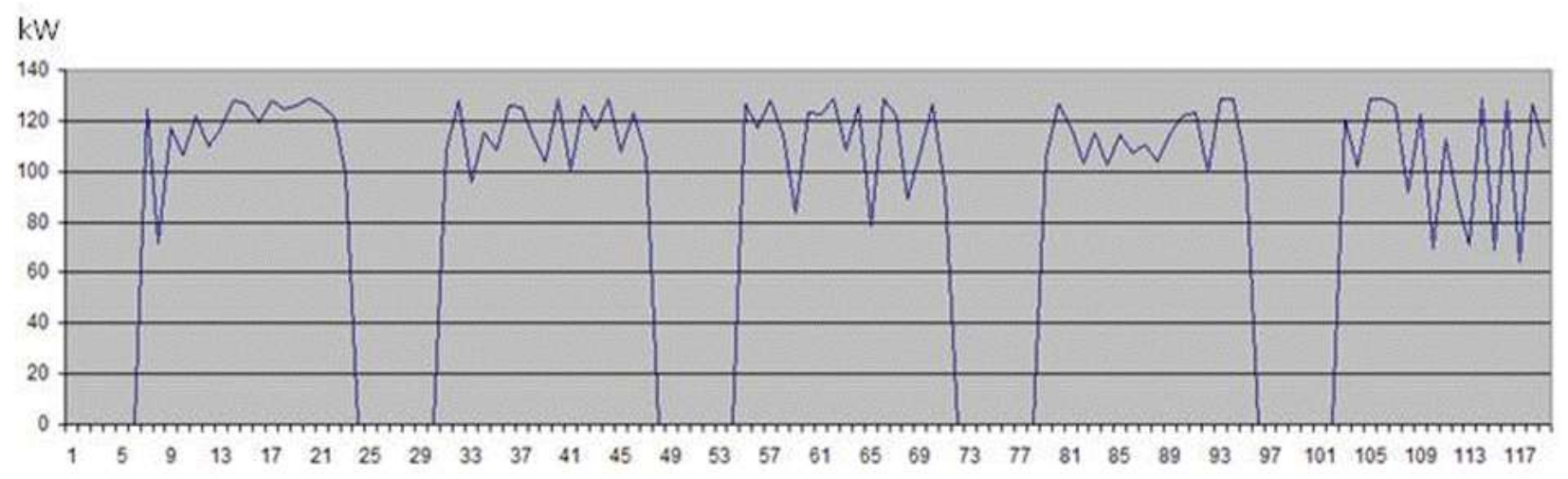

Figure 6 The result from the DES tool shows electricity consumption for Operation 1. 


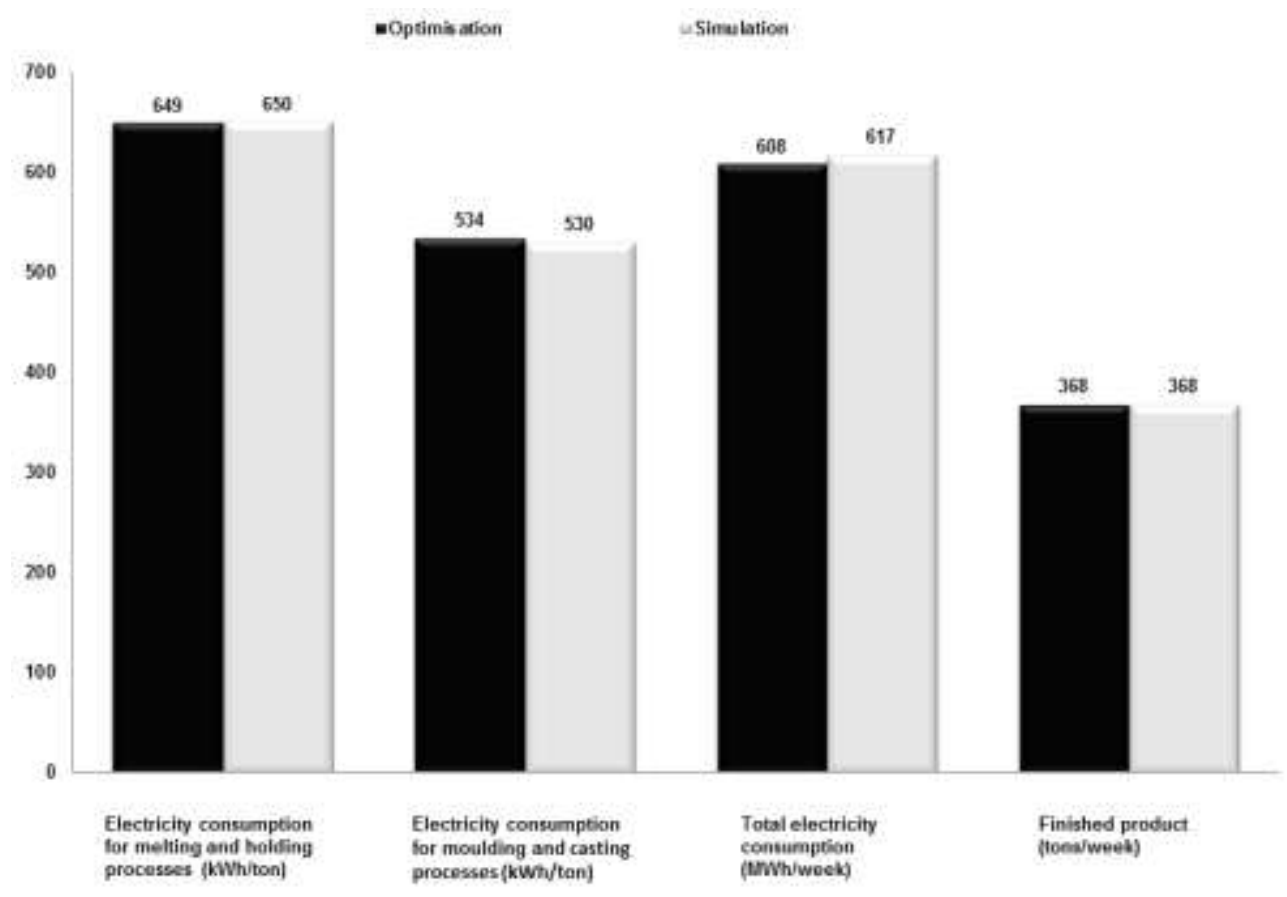

Figure 7 The results from simulation and optimisation tools for different processes after adjustment of the ESO model.

Electricity cost (using current electricity prices)

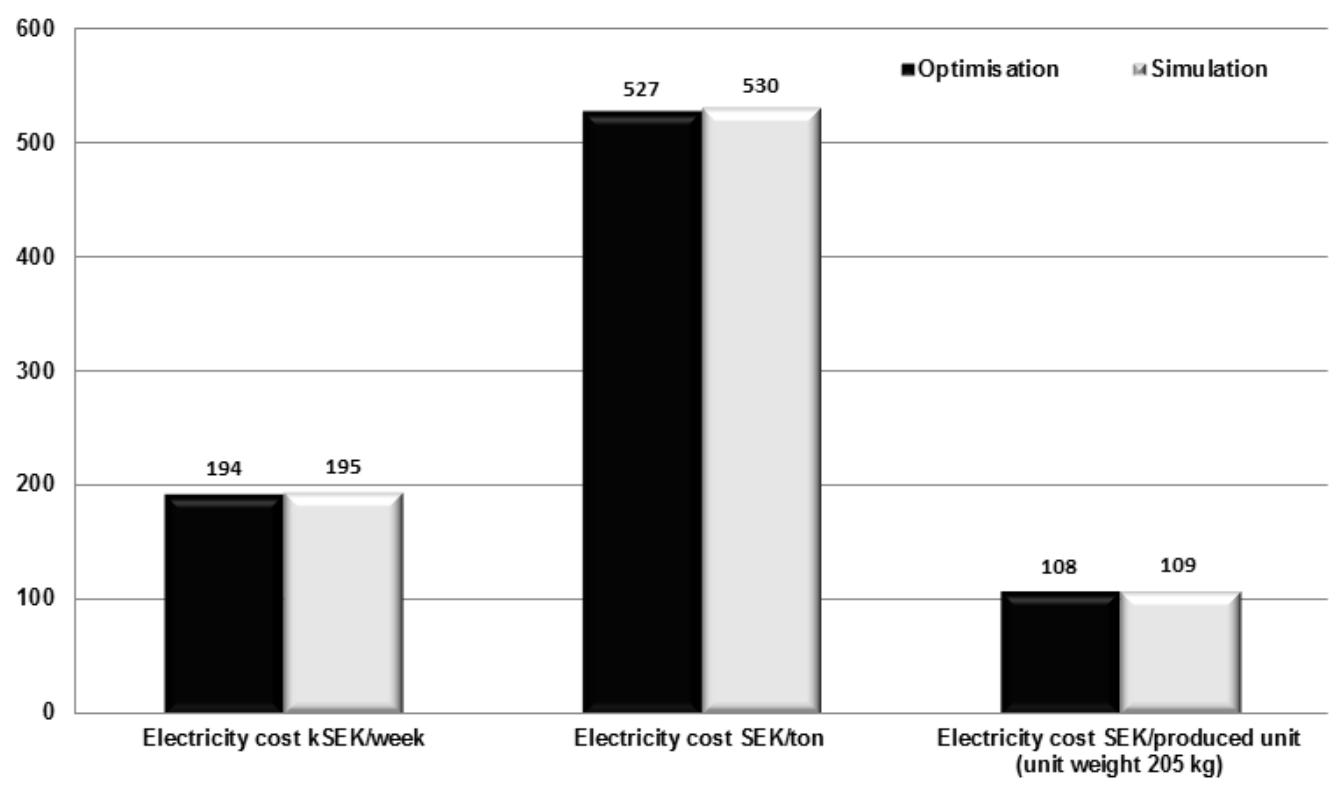

Figure 8 The electricity costs comparison from the DES and the ESO models for current electricity prices. 
The comparison of results in Figure 8 show that the energy cost per ton or per week from the DES and the ESO models is almost same, which indicates that the models validate each other's results.

To investigate how different boundary conditions affect the operational strategy both models are run (Steps 4 and 5) with future electricity prices, and a comparison of the results can be seen in Figure 9. The future electricity prices are 800 SEK/MWh during Monday to Friday between 6 a.m. and 6 p.m. and approximately 440 SEK/MWh during the rest of the week.

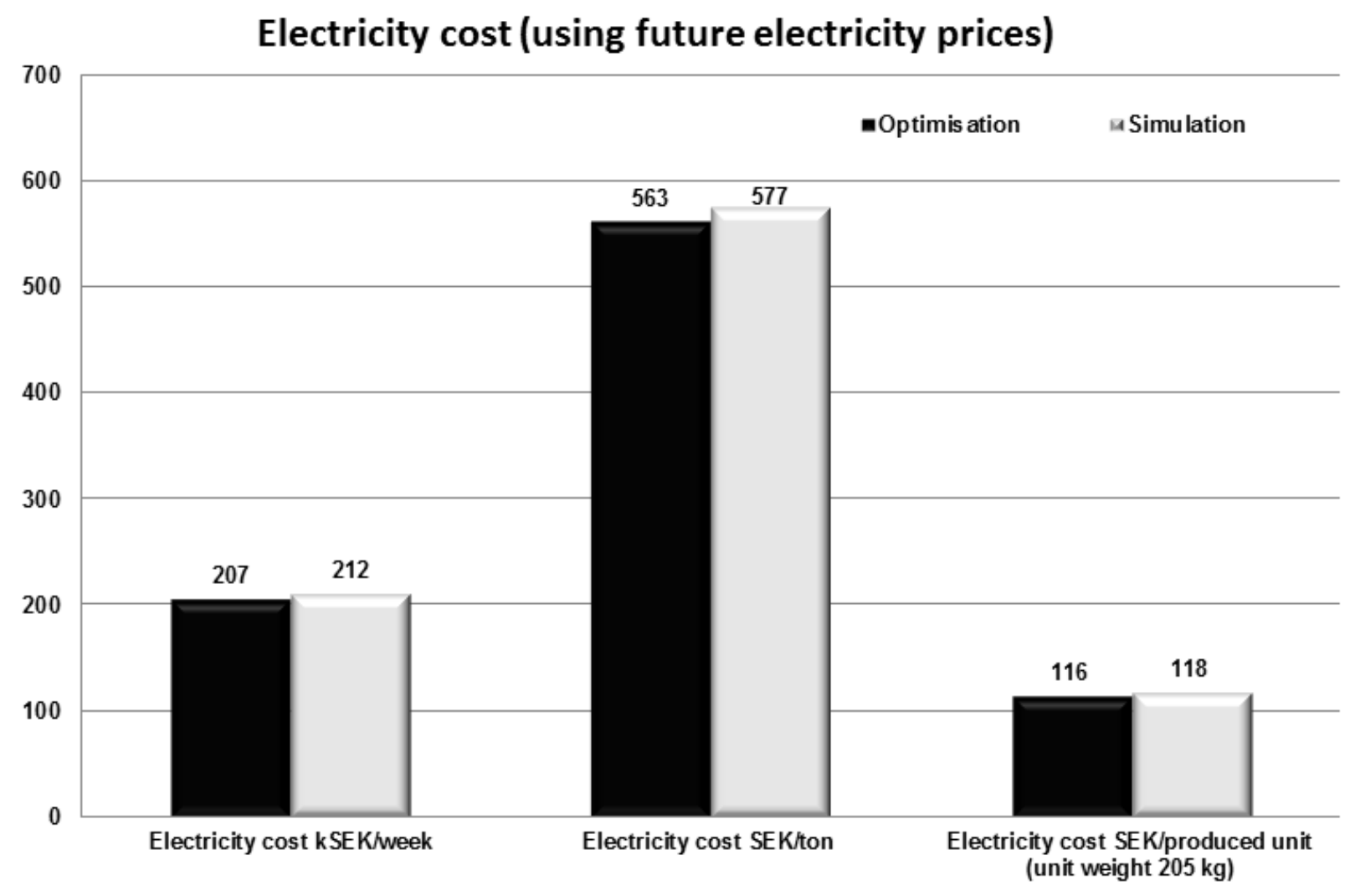

Figure 9 The electricity costs comparision from the DES and the ESO models for future electricity prices. 
Figure 9 shows that the energy costs from the DES model are higher than the cost from the ESO model, which indicates that the result from the DES model is not optimum. In order to achieve the same results in both models, the result from the ESO tool should be simulated in the DES tool (Step 5), i.e. the processes should be run in the manner that is proposed in the optimisation. The results from the optimisation indicated that the melting procedure takes place when electricity prices are low. This means that the excess capacity that exists in the melting furnaces is utilised by melting more in the evening, when electricity is cheaper. Molten iron is therefore kept in the holding furnace to be used in the pouring process later during the day. By turning off the melting furnaces for some periods during the day, when electricity prices are expensive, the same results are obtained in the simulation, see Figure 10.

\section{Concluding discussion}

Linking the above results to the aim and research question of this study, it is clear that the combination is depending on various issues, for example, if the issue is about an existing or non-existing system. For instance, if the issue is about a non-existent system, it is in general a good idea to use both the simulation and the optimization tool simultaneously, because there are many uncertain data that are difficult to estimate, by using only one of them. Both tools can support each other and more realistic output data regarding the dynamic changes that occur in the system such as blocking, idling, stopping, etc. can be obtained. 


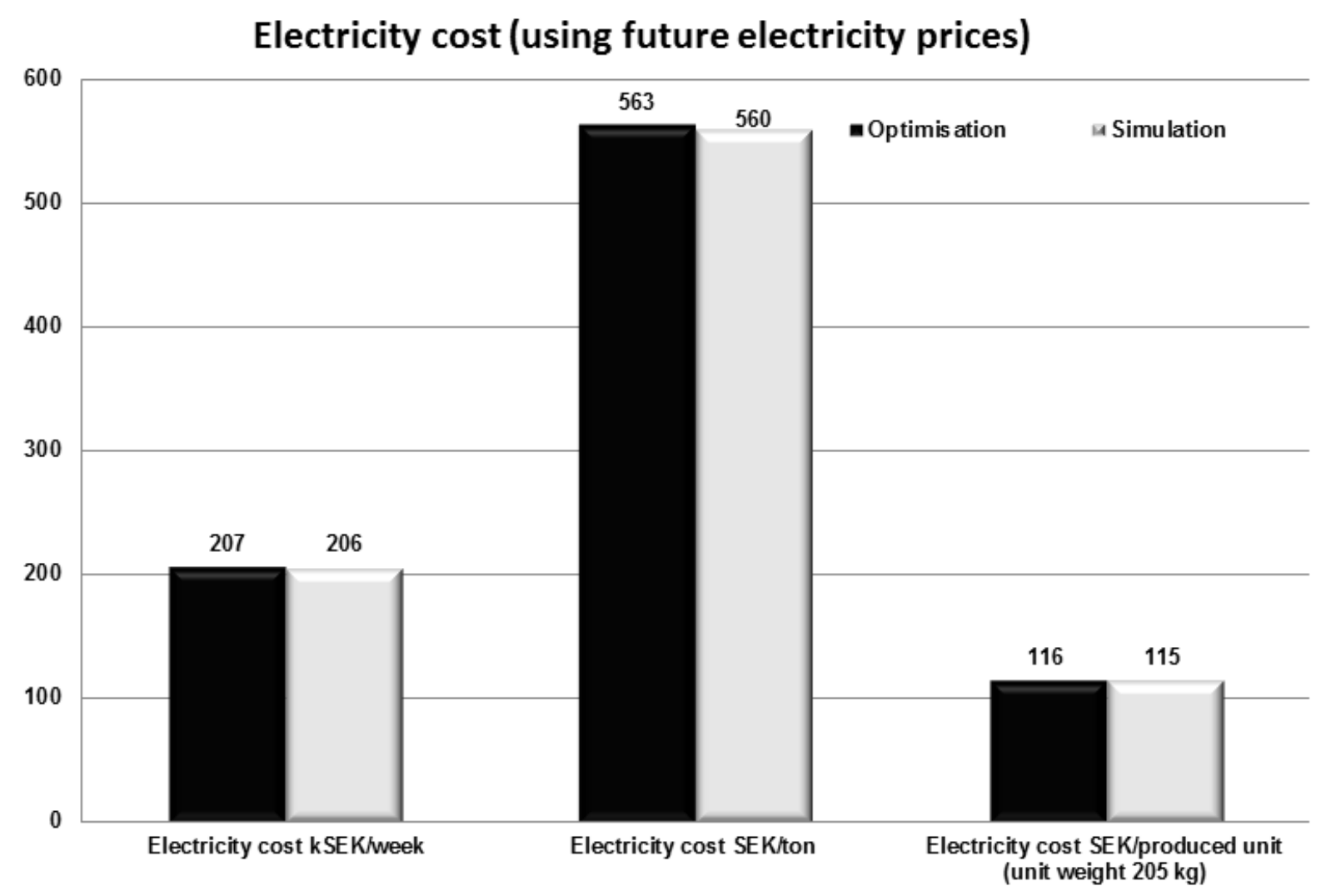

Figure 10 The electricity costs comparison from the DES and the ESO models for future electricity prices after adjustment of the DES model.

It should be taken into account the extra costs for the use of the ESO and DES tools in the combination, since it takes more time and resources to build the models. However, both simulation and optimisation are needed to obtain the necessary results to be able to make a good decision about the new planned investment. The two methods give a broader basis for discussions by generating more results. Decisions can be made faster and safer by the two methods confirming each other's results, in other words the methods can be used to validate and verify each other's model and results. The combination of the tools increases the reliability of the analysis, helps providing more information for the analysis than if the tools are used separately and facilitates decision making in an industrial site. There is 
also pedagogical usefulness due to the fact that the method combination gives a more complete picture of industrial reality.

From the above results, it can be seen clearly that combining DES and ESO tools is useful, can predict system behaviour, can give very detailed information about how the system works and decrease the system cost. The DES tool can give very detailed information about how the system operates, for example, information about the number of produced units per hour. On the other hand, the ESO tool can investigate if the result is optimum, in other words if the system is being operated in the best way. The results also show the importance of using the optimisation tool when different boundary conditions are used, because the results obtained from the simulation tool only showed feasibility and not the best way to run a factory. The results also show that the total energy usage may have a high value because some processes are always in operational mode and, as a result, the maximum amount of energy is used.

The combination method described in this study is based on the use of the DES tool QUEST and the ESO tool reMIND. The method itself is generic, i.e. other similar tools can also be used with some adaptations and adjustments.

\section{Acknowledgements}

The work was carried out as part of the research project INTegration of ENergy optimisation and discrete event Simulation (INTENS), which was financed by the Swedish Energy Agency (SEA). The main objective of the project was to combine mathematical energy optimisation with DES. We kindly thank the SEA for funding this project. We also would like to thank Tomas Haakon, at Volvo Powertrain, for his input in 
the discussions around the problem and the method used to solve it. We would also like to thank Mats Söderström and Magnus Karlsson, at Linköping University, for their valuable comments on the paper and Petter Solding, at SWEREA SWECAST, for his input to the discussions on earlier drafts of this paper.

\section{References}

[1] Intergovernmental Panel on Climate Change. Fourth Assessment Report, 2007. http://www.ipcc.ch [accessed 03-02-2011].

[2] Thollander P., Mardan N., Karlsson M. Optimization as investment decision support in a Swedish medium-sized iron foundry - A move beyond traditional energy auditing, Applied Energy 2009; 86(4): 433-40.

[3] Kong H., Qi E., Li H., Li G., Zhang X. An MILP model for optimization of byproduct gases in the integrated iron and steel plant. Applied Energy 2010; 87(7): 2,156-2,163.

[4] Sandberg P., Larsson M., Dahl J., Söderström M., Vourinen H. In search of stability investigating flexible and stable production strategies for an optimised steel plant, Scanmet II, Proceedings of the 2nd international Conference on Process Development in Iron and Steel making, Luleå, Sweden, 2004.

[5] Marshman D.J., Chmelyk T., Sidhu M.S., Gopaluni R.B., Dumont G.A. Energy optimization in a pulp and paper mill cogeneration facility, Applied Energy 2010; 87(11): $3,514-3,525$. 
[6] Karlsson M., Söderström M. Sensitivity analysis of investments in the pulp and paper industry - on investments in the chemical recovery cycle at a board mill. International Journal of Energy Research, Wiley, 2002; 26(14).

[7] Wetterlund E., Söderström M. Biomass gasification in district heating systems - the effect of economic energy policies. Applied Energy 2010; 87(9): 2914-2922.

[8] Münster M., Meibom P. Optimization of use of waste in the future energy system, Energy 2011; 36(3): 1612-1622.

[9] Gutiérrez-Alcaraz G., Sheblé G.B. Modeling energy market dynamics using discrete event system simulation, Energy 2009; 34(10): 1467-1476.

[10] Mobini M., Sowlati T., Sokhansanj S. Forest biomass supply logistics for a power plant using the discrete-event simulation approach, Applied Energy 2011; 88(4): 12411250.

[11] Solding P., Thollander P., Moore P. Improved energy-efficient production using discrete event simulation. Journal of Simulation 2009; 3(4): 191-201.

[12] Solding P. More energy efficient casting without loss of output. 68th World Foundry Congress, Chennai, India, 2008.

[13] Solding P. Increased Energy Efficiency in Manufacturing Systems Using Discrete Event Simulation - Applied Studies on the Swedish Foundry Industry. PhD dissertation, Computing Sciences and Engineering, De Montfort University, UK, 2008. 
[14] Solding P., Thollander P. Increased energy efficiency in a Swedish iron foundry through use of discrete event simulation. Proceedings of the 2006 Winter Simulation Conference, Monterey, USA, 2006.

[15] Robinson S. Successful Simulation: A Practical Approach to Simulation Projects. McGraw-Hill Book Company Europe, Berkshire, England, 1994.

[16] AlDurgham, M.M., Barghash, M.A., A generalised framework for simulation-based decision support for manufacturing, Production Planning and Control, 19 (5), pp. 518$534,2008$.

[17] Kursun, S., Kalaoglu, F., Simulation of production line balancing in apparel manufacturing, Fibres and Textiles in Eastern Europe, 75 (4), pp. 68-71, 2009.

[18] Mardan N., Karlsson M., Solding P. Benefits of integration of energy systems optimization and discrete event simulation. Submitted to Applied Energy 2010.

[19] Shi X. Design optimization of insulation usage and space conditioning load using energy simulation and genetic algorithm, Energy 2011; 36(3): 1659-1667.

[20] Roy A., Kedare S. B., Bandyopadhyay S. Optimum sizing of wind-battery systems incorporating resource uncertainty, Applied Energy 2010; 87(8): 2712-2727.

[21] Sudiro M., Bertucco A. Production of synthetic gasoline and diesel fuel by alternative processes using natural gas and coal: Process simulation and optimization, Energy 2009; 34(12): 2206-2214. 
[22] Ekren B. Y., Ekren O. Simulation based size optimization of a PV/wind hybrid energy conversion system with battery storage under various load and auxiliary energy conditions, Applied Energy 2009; 86(9): 1387-1394.

[23] Masoumi M.E., Sadrameli S.M., Towfighi J., Niaei A. Simulation, optimization and control of a thermal cracking furnace, Energy 2006; 31(4): 516-527.

[24] Fong K.F., Lee C.K., Chow C.K., Yuen S.Y. Simulation-optimization of solarthermal refrigeration systems for office use in subtropical Hong Kong, Energy 2011, 36(11): 6298-6307.

[25] Luo X., Zhang B., Chen Y., Mo S. Modeling and optimization of a utility system containing multiple extractions steam turbines, Energy 2011, 36(5): 3501-3512.

[26] Harkin T., Hoadley A., Hooper B. Using multi-objective optimisation in the design of CO2 capture systems for retrofit to coal power stations, Energy 2011, In Press.

[27] Ma T., Nakamori Y. Modeling technological change in energy systems - From optimization to agent-based modeling, Energy 2009, 34(7): 873-879.

[28] Petku D., Mardan N., Solding P. Software aided collection methodology. Proceedings of the FAIM2008 "Flexible Automation and Intelligent Manufacturing" Conference, Skövde, Sweden, 2008: 1032 - 1036.

[29] Solding P., Petku D., Mardan N. Using simulation for more sustainable production systems - methodologies and case studies. International Journal of Sustainable Engineering 2009; 2(2): 111-122. 
[30] Nilsson K. Cost-effective industrial energy systems - multiperiod optimizations of operating strategies and structural choices. Thesis No. 315, Division of Energy Systems, Linköping University, Sweden, 1993.

[31] Karlsson M., Mardan N. Timing and sizing of investments in industrial processes the use of an optimization tool. Proceedings of the ECOS2010 "23rd International Conference on Efficiency, Cost, Optimization, Simulation and Environmental Impact of Energy Systems”, Lausanne, Switzerland, 2010.

[32] Karlsson M. The MIND method: a decision support for optimization of industrial energy systems - principles and case studies. Applied Energy 2011; 88(3): 577-589.

[33] Wang C., Ryman C., Dahl J. Potential $\mathrm{CO}_{2}$ emission reduction for BF-BOF steelmaking based on optimised use of ferrous burden materials. International Journal of Greenhouse Gas Control 2009; 3(1): 29-38.

[34] Svensson I., Jönsson J., Berntsson T., Moshfegh B. Excess Heat from Chemical Pulp Mills: Trade-offs between Internal and External Use in the Case of Sweden - Part 1: Methodology. Energy Policy 2008; 36(11): 4178-4185.

[35] Ryman C., Larsson M. Reduction of $\mathrm{CO}_{2}$ emissions from integrated steel-making by optimised scrap strategies: Application of process integration models on the BF-BOF system. ISIJ International 2006; 46(12): 1752-1758.

[36] Larsson M., Dahl J. Reduction of the specific energy use in an integrated steel plant - The effect of an optimisation model. ISIJ International 2003; 43(10): 1664-1673. 
[37] Larsson M., Sandberg P., Dahl J., Söderström M., Vourinen H. System gains from widening the system boundaries: analysis of the material and energy balance during renovation of a coke oven battery. International Journal for Energy Research, 2004, 28(12): 1051-1064.

[38] CPLEX Optimization Inc, Using the CPLEX Callable Library, CPLEX Optimization Inc., Incline Village, USA, 1995.

[39] Klugman, S., Karlsson, M. and Moshfegh, B., A Swedish integrated pulp and paper mill - Energy optimisation and local heat cooperation, Energy Policy, 37(7), pp 25142524, 2009.

[40] DELMIA Digital Manufacturing \& Production. Available from: http://www.delmia.com [accessed 03.03.2011].

[41] AB Volvo. Press Information - Volvo's foundry awarded for effective energy initiatives. Göteborg, Sweden: AB Volvo Publications, 2007.

[42] Melkerson M., Söderberg S.O. Dynamiska Elpriser - elprissättning på en integrerad europeisk elmarknad [Dynamic electricity prices - pricing in a integrated European electricity-market]. Master's thesis, Division of Energy Systems, Linköping University, Sweden; 2004 [in Swedish]. 